\title{
Metabolic syndrome in central Brazil: prevalence and correlates in the adult population
}

\author{
Eliane Said Dutra ${ }^{1}$, Kênia Mara Baiocchi de Carvalho², Édina Miyazaki ${ }^{3}$ Edgar Merchán- Hamann ${ }^{4}$ and \\ Marina Kiyomi Ito $^{1 *}$
}

\begin{abstract}
Background: The prevalence of metabolic syndrome (MetS) has increased in developing countries in recent decades. This syndrome, a clustering of metabolic abnormalities, has been correlated to various socioeconomic and behavioral variables. We investigated the prevalence and prevalence ratios (PR) of MetS and related factors in an adult population of the Federal District (FD) of Brazil, which is located in the central region of the country.
\end{abstract}

Methods: A cross-sectional, population-based study conducted in 2007, with 2130 adults (aged 18 years or older) in the FD of Brazil. Metabolic syndrome was defined according to the recently harmonized criteria. The prevalence of MetS and PR were estimated for each sex according to the diagnostic components and the overall contribution of the selected correlates.

Results: The overall prevalence of MetS was 32.0\% (95\%Cl: 28.9-35.2), with no gender difference. The single component with the greatest contribution to the diagnosis of MetS was hypertension in men (PR 5.10, 95\%Cl: 3.17-8.22) and high waist circumference in women (PR 5.02,95\%Cl: 3.77-6.69). The prevalence of MetS increased significantly and progressively with age and excess weight. In women, higher education was protective against MetS (PR 0.66, 95\%Cl: 0.49-0.89) compared to 8 or less years of education. There was no association between the prevalence of MetS and behavioral variables studied.

Conclusions: This study provides comprehensive and alarming data about the prevalence of MetS among the adult population of Brazil's FD. The results suggest that reducing education inequalities may be an important public policy goal to improve health outcomes, especially among women.

Keywords: Metabolic syndrome, Prevalence, Developing country, Education, Brazil

\section{Background}

The burden of chronic non-communicable diseases (NCD) in developing countries continues to rise, with high morbidity and mortality due to cardiovascular diseases (CVD) $[1,2]$. Metabolic syndrome (MetS) is a complex disorder characterized by the association of cardiovascular risk factors and insulin resistance. The factors that define MetS include central obesity, dyslipidemia, hypertension and altered glucose metabolism [3]. The risk associated with CVD and type 2 diabetes increases as a cluster [4-6] or in accordance with individual components of MetS [7,8]. While debate continues over the definition of MetS, its

\footnotetext{
* Correspondence: marina@unb.br

'Programa de Pós-graduação em Ciências da Saúde, Faculdade de Ciências da Saúde, Universidade de Brasília, Campus Darcy Ribeiro, Brasília, DF 70910900, Brazil

Full list of author information is available at the end of the article
}

clinical significance and value as an independent risk marker for cardiovascular disease (CVD) remains high $[9,10]$.

Likewise, the public health relevance of MetS for countries in which economic resources are limited is unquestionable. Government policies to prevent CVD may be optimized when aimed to prevent and treat MetS as a whole rather than its individual risk factors [11].

Globally, the overall prevalence of MetS may vary according to the population, gender, age, geographic location, other correlated variables and the diagnostic criteria used [12,13]. In addition, its prevalence has increased in developing countries in recent decades [11]. The Cardiovascular Risk Factor Multiple Evaluation in Latin America (CARMELA) study included an assessment of MetS in seven urban Hispanic Latin American adult populations. The prevalence of MetS, defined

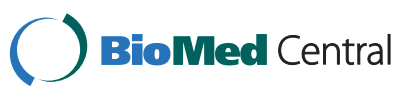


according to the National Cholesterol Education Program Adult Treatment Panel III - NCEP/ATP III [14], was highest among CARMELA cities in Mexico City (27\%) and lowest in Quito (14\%) [15].

Underprivileged urban populations from developing countries have been shown to have an increased prevalence of overweight [16] and other risk factors for CVD [11]. Brazil is a non-Hispanic middle income country, and CVD is the leading cause of mortality there. Low income segments of the population are the most affected, especially with respect to premature deaths attributable to CVD [17]. In the few population studies conducted in Brazil, MetS prevalence ranged from 19\% [18] to $25 \%$ [19] in urban populations. Among socioeconomic factors, educational inequality has consistently been associated with an increased risk of MetS in different populations [11,20,21], but this association has not been demonstrated for the South American population.

Recently, to simplify the diagnostic process and allow for comparison between countries, a unifying world-wide consensus definition for MetS was proposed [3]. According to the harmonized criteria, population and country-specific definitions for waist circumference thresholds should be used.

The aim of this study was to use the new consensus definitions to estimate the prevalence and prevalence ratios (PR) of MetS in the adult population of Brazil's Federal District (FD), which includes the capital city Brasilia. Furthermore, the study sought to investigate the associated correlates for MetS prevalence in a sample with a wider age range.

\section{Methods}

Brazil's FD is located in the center of the country, with a population of 2,434,033 inhabitants, $68.9 \%$ of whom are 18 years or older [22]. The population has a diverse background, including people who were born locally and those who came from other parts of the country during the 50 years of the FD's existence. This population-based household cross-sectional study representative of the population aged 18 years or older residing in the FD was conducted in 2007 to investigate the prevalence and risk factors associated with NCD. The study used a complex sampling plan with a multistage probability cluster design and with random sampling of census sectors, households and one adult per household in urban and rural areas of the FD [22]. The sample loss was considered to be $20 \%$. Pregnant women and adults unable to understand or respond independently were excluded from the survey. Of the 2,726 adults that comprised the study sample, 2,130 individuals constituted the final sample that had anthropometric measurements taken and biochemical tests performed.
The study protocol was approved by the University of Brasilia's Faculty of Health Sciences Research Ethics Committee, and informed consent was obtained from each participant. Household questionnaires were administered in face-to-face interviews. Interviewers were trained health sciences students or professionals. Reproducibility tests were conducted to guarantee reliable instrument and interviewer performance.

Anthropometric measurements were obtained twice with the participant in light clothing and barefoot. Body weight was measured using a digital scale, and height was determined by a portable stadiometer for body mass index (BMI) calculation $\left(\mathrm{kg} / \mathrm{m}^{2}\right)$. Waist circumference (WC) was measured to the nearest millimeter and taken midway between the lower limit of the rib cage and the iliac crest using a non-stretchable nylon tape. Arterial blood pressure readings were measured twice (15 min interval) in a seated position with an automatic apparatus (Omron, model HEM-705CP, USA), and the mean of the two values was calculated.

For biochemical tests, $12 \mathrm{~h}$ overnight fasting blood samples were assayed by standard methods for glucose, total cholesterol (TC), high-density lipoprotein cholesterol (HDLc) and triglycerides (TG) using an automatic biochemical analyzer Konelab 60i (Thermo Electron Co., USA). Low-density lipoprotein cholesterol (LDLc) was calculated by the Friedewald equation, excluding samples with triglyceride values $>400 \mathrm{mg} / \mathrm{dL}$ [23].

This study used the harmonized MetS criteria [3]. Metabolic syndrome (the dependent variable) was considered present when at least three of the following characteristics were observed: TG $\geq 150 \mathrm{mg} / \mathrm{dL}$; HDLc $<40 \mathrm{mg} / \mathrm{dL}$ in men or $<50 \mathrm{mg} / \mathrm{dL}$ in women; systolic arterial blood pressure $\geq 130 \mathrm{mmHg}$ and/or diastolic arterial blood pressure $\geq 85 \mathrm{mmHg}$ or anti-hypertensive treatment; and glucose $\geq 100 \mathrm{mg} / \mathrm{dL}$ or anti-diabetic treatment. For abdominal obesity, the consensus calls for the "population- and country- specific definition" of cut points for elevated WC. No WC cut point of risk for MetS has been established for the Brazilian population as a whole. As Brazilians are predominantly of European ancestry [24], we adopted WC threshold values of $\geq 102 \mathrm{~cm}$ for men and $\geq 88 \mathrm{~cm}$ for women, one of the criteria recommended by the harmonized consensus based on American Heart Association/National Heart, Lung and, Blood Institute values for people of European origin [3].

The independent variables included socio-demographic, behavioral, nutritional and health status. Sociodemographic variables included age, sex, education, per capita income (legal minimal wage $(\mathrm{MW})$ at the time of the field work $\approx$ US\$150.00), time of residence in FD, marital status and selfreported skin color. Behavioral variables were fruit and vegetable intake, use of table salt, alcohol consumption and smoking status. Physical activity level was assessed by the 
International Physical Activity Questionnaire short version [25] and categorized into sufficiently active, insufficiently active and inactive [26]. Aside from MetS defining factors, the additional nutritional and health variables were BMI, TC and LDLc.

\section{Statistical analysis}

To estimate the prevalence of MetS and associated factors, weighting factors were used so that a probability of being sampled was assigned to each participant. This procedure enabled the results to represent the adult population of FD according to sex, age and education level based on the official census data available at the time of analysis [21].

The database was built by double typing. Sample weights and the effect of complex sample design on the standard errors were treated using the survey command of STATA software version 9.2 (Stata Corp., College Station, Texas, USA). Initially, the prevalence of MetS and the number of MetS-defining components were calculated as well as the socio-demographic variable distributions with 95\% confidence intervals (CI). Next, two multivariate models were tested. In the first model, the prevalence ratios (PR) between each diagnostic component and the MetS diagnosis with 95\% CI were calculated to analyze the strength of the association between each MetS-defining component and diagnosis. The second model analyzed the overall contribution of all the independent variables to MetS diagnosis excluding the MetS-defining variables. In this model, after the initial crude analysis, the variables with a significant association with MetS were further adjusted. All the multivariate analyses were carried out using a Poisson regression with robust variance (log-linear) for each sex. We used the Poisson regression because it provides a better estimate of the prevalence ratios, which in turn represent a more meaningful effects measure for cross-sectional studies [27]. The significance level was set at $P$-value $<0.05$.

\section{Results}

The overall prevalence of MetS was $32.0 \%$, with no difference observed between men (30.9\%, 95\%CI: 26.135.6) and women (33.0\%, 95\%CI: 29.5-36.6). According to the number of diagnostic components of MetS, only $13.6 \%$ had zero components, and $5.2 \%$ had all five components (Table 1). The majority of subjects in the study were female, younger than 45 years old, with a per capita income below one minimum wage, married or living with a partner, and $50 \%$ had up to 8 years of schooling. The most frequently cited self-reported skin color category was "mixed" (44.8\%).

Table 2 summarizes the contribution of individual diagnostic components to the observed PR for MetS. The single crude component that contributed most to the diagnosis of MetS was hypertension or elevated blood pressure in men (PR 11.01, 95\%CI: 6.41-18.93) and high WC in women (PR 11.26, CI95\%: 8.55-14.83). Adjustment for all diagnostic components did not change these results, and a high WC led to a greater than five-fold increase in the prevalence of MetS among women (PR 5.02, CI95\%: 3.77-6.69). The other two most important components that increased MetS prevalence were hypertriglyceridemia and low HDLc in men and low HDLc and elevated blood pressure in women.

Tables 3 and 4 present PR according to sociodemographic, behavioral and selected health variables. In the crude PR analysis, the following variables did not show significance and were excluded: education, per capita income, skin color, fruit and vegetable intake, extra table salt, alcohol consumption, smoking and LDLc levels (for males); and per capita income, skin color, fruit and vegetable intake and current physical activity level (for females; data not shown). Subsequently, in the multivariate analysis, the first adjustment was performed for age. Among men (Table 3), variables that showed significance at this level were age, BMI and TC. For women (Table 4), age, education, marital status, alcohol consumption, BMI and TC were significantly associated with MetS.

After the final adjustment, the prevalence of MetS increased significantly and progressively with age $(P<0.001)$ and $\mathrm{BMI} \geq 25 \mathrm{~kg} / \mathrm{m}^{2}(P<0.001)$ in both men and women. For women (Table 4 ), there was a $20 \%$ increase in the frequency of MetS in those with total cholesterol levels greater than or equal to $200 \mathrm{mg} / \mathrm{dL}(P<0.05)$. Only in women, higher education (12 or more years of study) was protective against MetS (PR 0.66, 95\% CI: $0.49-0.89$ ). Younger women tended to have more than 12 years of education when compared to older women (results not shown). No association was observed between behavioral variables and the prevalence of MetS.

\section{Discussion}

To our knowledge, this is the first published populationbased study that determined the prevalence of MetS in Central Brazil. The results indicate that the population of the FD is at significant risk of morbidity and mortality from CVD and type 2 diabetes due to the high prevalence of MetS (32.0\%). This disturbing result is not surprising because trends of excess weight among Brazilians [28] and the country's surveillance system have pointed to the increasing prevalence of excess weight and other factors associated with cardiovascular risk in our adult population [29]. Our results reinforce an alarming public health trend $[16,17]$.

The overall prevalence of MetS found in our study is similar to that in the US population (34.0\%) reported by the 2003-2006 National Health and Nutrition Examination Survey (NHANES) [30]. Compared to other middle 
Table 1 Prevalence and distribution of sociodemographic variables (\%), metabolic syndrome (MetS) and number of its components, among adults aged 18 years or older a (Federal District, Brazil, 2007)

\begin{tabular}{|c|c|c|c|c|c|c|}
\hline \multirow[b]{2}{*}{ Variable } & \multicolumn{2}{|c|}{ Total $(n=2130)$} & \multicolumn{2}{|c|}{ Male $(n=586)$} & \multicolumn{2}{|c|}{ Female $(n=1544)$} \\
\hline & $\%$ & $95 \% \mathrm{Cl}$ & $\%$ & $95 \% \mathrm{Cl}$ & $\%$ & $95 \% \mathrm{Cl}$ \\
\hline \multicolumn{7}{|l|}{ MetS } \\
\hline No & 68.0 & $(64.8-71.1)$ & 69.1 & $(64.4-73.9)$ & 67.0 & $(63.4-70.5)$ \\
\hline Yes & 32.0 & $(28.9-35.2)$ & 30.9 & $(26.1-35.6)$ & 33.0 & $(29.5-36.6)$ \\
\hline \multicolumn{7}{|l|}{ MetS components number } \\
\hline 0 & 13.6 & $(11.2-159)$ & 14.8 & $(10.3-19.2)$ & 12.5 & $(10.0-15.0)$ \\
\hline 1 & 31.8 & $(28.6-35.1)$ & 31.2 & $(25.5-36.9)$ & 32.4 & $(28.0-36.8)$ \\
\hline 2 & 22.6 & $(19.9-25.2)$ & 23.2 & $(19.1-27.2)$ & 22.0 & $(18.9-25.2)$ \\
\hline 3 & 15.7 & $(13.6-17.8)$ & 15.2 & $(12.0-18.4)$ & 16.1 & $(13.8-18.5)$ \\
\hline 4 & 11.1 & $(9.3-12.8)$ & 10.5 & $(8.0-13.1)$ & 11.6 & $(9.4-13.7)$ \\
\hline 5 & 5.2 & $(4.0-6.5)$ & 5.1 & $(3.0-7.2)$ & 5.3 & $(4.1-6.6)$ \\
\hline \multicolumn{7}{|l|}{ Age (years) } \\
\hline $18-24$ & 24.8 & $(20.9-28.8)$ & 25.3 & $(18.2-32.3)$ & 24.5 & $(21.2-27.7)$ \\
\hline $25-34$ & 28.6 & $(24.5-32.7)$ & 28.9 & $(20.8-37.1)$ & 28.3 & $(24.4-32.2)$ \\
\hline $35-44$ & 21.1 & $(18.4-23.8)$ & 20.8 & $(16.5-25.2)$ & 21.3 & $(18.8-23.7)$ \\
\hline $45-54$ & 13.4 & $(11.8-15.1)$ & 13.3 & $(10.4-16.2)$ & 13.5 & $(11.5-15.5)$ \\
\hline $55-64$ & 7.1 & $(5.9-8.2)$ & 7.2 & $(5.4-9.0)$ & 7.0 & $(5.8-8.2)$ \\
\hline$\geq 65$ & 5.0 & $(3.5-6.5)$ & 4.5 & $(2.8-6.2)$ & 5.5 & $(4.0-6.9)$ \\
\hline \multicolumn{7}{|l|}{ Education (years) } \\
\hline $0-8$ & 50.1 & $(42.8-57.5)$ & 51.9 & $(43.3-60.5)$ & 48.6 & $(41.3-55.8)$ \\
\hline $9-11$ & 31.3 & $(27.5-35.2)$ & 29.3 & $(24.6-34.1)$ & 33.1 & $(28.9-37.3)$ \\
\hline$\geq 12$ & 18.5 & $(10.3-26.8)$ & 18.8 & $(10.0-27.6)$ & 18.3 & $(10.0-26.6)$ \\
\hline \multicolumn{7}{|c|}{ Per capita income (minimal wages) } \\
\hline$<0.5$ & 31.6 & $(24.3-38.9)$ & 23.9 & $(15.5-32.2)$ & 38.4 & $(29.9-47.0)$ \\
\hline $0.5-1.0$ & 25.1 & $(20.3-29.9)$ & 25.1 & $(17.8-32.4)$ & 25.2 & $(20.6-29.8)$ \\
\hline$>1.0$ & 43.3 & $(33.9-52.6)$ & 51.1 & $(40.6-61.6)$ & 36.3 & $(26.3-46.4)$ \\
\hline \multicolumn{7}{|l|}{ Marital status } \\
\hline Single & 35.0 & $(30.8-39.2)$ & 40.0 & $(32.7-47.3)$ & 30.6 & $(26.5-34.6)$ \\
\hline Married/living with partner & 56.4 & $(52.4-60.4)$ & 54.6 & $(47.1-62.1)$ & 58.0 & $(53.3-62.6)$ \\
\hline Widowed/separated & 8.6 & $(6.9-10.3)$ & 5.4 & $(2.7-8.0)$ & 11.4 & $(9.3-13.6)$ \\
\hline \multicolumn{7}{|l|}{ Skin color } \\
\hline Black & 14.1 & $(11.1-17.1)$ & 15.6 & $(10.7-20.5)$ & 12.1 & $(7.9-16.4)$ \\
\hline Mixed ("pardo") & 44.8 & $(38.6-51.0)$ & 47.2 & $(37.8-56.6)$ & 42.7 & $(37.1-48.3)$ \\
\hline White & 30.3 & $(23.5-37.2)$ & 28.0 & $(18.9-37.2)$ & 32.3 & $(26.3-38.3)$ \\
\hline Others & 10.8 & $(6.3-15.2)$ & 9.2 & $(3.7-14.7)$ & 12.1 & $(7.9-16.4)$ \\
\hline
\end{tabular}

a Weighted to represent distributions of population aged 18 years or older, according to gender, age and education based on Brazilian national census for the year 2000.

income countries, our result is similar to Venezuela, with $31.2 \%$, [31] greater than the $26.9 \%$ described for Peru [32], and lower than the $41.4 \%$ reported in India [33]. Apart from methodological differences between studies, variability in the prevalence of MetS between populations could be explained by demographic, epidemiological and nutritional transitions [34], as well as environmental and social influences [35], and ethnic differences [36]. As for the prevalence of MetS compared to other Brazilian studies, the results of this study may reflect the differences in the statistical analyses $[18,19]$ and fasting glucose cut-off points [18]. Additionally, regional differences and the period of data collection (for example the early 2000s) are factors that deserve consideration.

There is a gradient of risk for CVD with increasing number of MetS components [37,38]. The identification of persons with zero diagnostic criteria of MetS, a group that comprised $13.6 \%$ of our study population, is clinically 
Table 2 Crude and adjusted prevalence ratios of metabolic syndrome according to diagnostic components among adults aged 18 years or older ${ }^{a}$, by gender (Federal District, Brazil, 2007)

\begin{tabular}{|c|c|c|c|c|c|c|c|c|}
\hline & \multicolumn{8}{|c|}{ Prevalence ratio $(95 \% \mathrm{Cl})$} \\
\hline & \multicolumn{4}{|c|}{ Male } & \multicolumn{4}{|c|}{ Female } \\
\hline & \multicolumn{2}{|c|}{ Crude } & \multicolumn{2}{|c|}{ Adjusted $^{\mathbf{b}}$} & \multicolumn{2}{|r|}{ Crude } & \multicolumn{2}{|r|}{ Adjusted $^{\mathbf{b}}$} \\
\hline \multicolumn{9}{|c|}{ Elevated blood pressure } \\
\hline No & 1 & & 1 & & 1 & & 1 & \\
\hline Yes & 11.01 & $(6.41-18.93)$ & 5.10 & $(3.17-8.22)$ & 6.29 & $(4.96-7.98)$ & 2.45 & $(2.02-2.97)$ \\
\hline \multicolumn{9}{|c|}{ Elevated fasting glucose } \\
\hline No & 1 & & 1 & & 1 & & 1 & \\
\hline Yes & 4.62 & $(3.52-6.05)$ & 1.80 & $(1.47-2.20)$ & 3.98 & $(3.40-4.65)$ & 1.53 & $(1.36-1.72)$ \\
\hline \multicolumn{9}{|c|}{ Elevated waist circunference } \\
\hline No & 1 & & 1 & & 1 & & 1 & \\
\hline Yes & 4.92 & $(3.81-6.36)$ & 1.63 & $(1.30-2.03)$ & 11.26 & $(8.55-14.83)$ & 5.02 & $(3.77-6.69)$ \\
\hline \multicolumn{9}{|c|}{ Elevated triglycerides } \\
\hline No & 1 & & 1 & & 1 & & 1 & \\
\hline Yes & 6.78 & $(4.28-10.72)$ & 3.03 & $(2.26-4.86)$ & 4.32 & $(3.64-5.13)$ & 1.84 & $(1.63-2.08)$ \\
\hline \multicolumn{9}{|c|}{ Low HDLC } \\
\hline No & 1 & & 1 & & 1 & & 1 & \\
\hline Yes & 5.82 & $(3.49-9.71)$ & 2.97 & $(1.95-4.51)$ & 4.63 & $(3.32-6.44)$ & 2.71 & $(2.14-3.45)$ \\
\hline
\end{tabular}

relevant as these people seem to have a substantially reduced risk of developing CVD [39]. Those without any risk should be an important target for the identification of the beneficial factors associated with protection against MetS.

The difference between genders in which three components most strongly accounted for the diagnosis of MetS in our sample was unexpected (Table 2). The practical utility of this information is the knowledge that hypertension in men and abdominal obesity in women could be the single best predictors of MetS related co-morbidity for screening purposes.

Although the World Health Organization [40] identified environmental factors such as smoking, low intake of fruit and vegetables, physical inactivity, and other factors as important contributors to a large proportion of mortality attributed to CVD, no association was observed between behavioral correlates and MetS in the present study (Tables 3 and 4). Similar results were described in a recent cohort study for MetS in Portugal [41], and these results point to the complex nature of MetS-associated factors.

The strong association between abdominal obesity and MetS is well-recognized [42,43]. In the unified statement on the definition of MetS, the WC is the only parameter to be evaluated according to population and country-specific definitions [3]. The unified consensus suggests $W C \geq 90 \mathrm{~cm}$ for male and $\geq 80 \mathrm{~cm}$ for female as thresholds for abdominal obesity among ethnic South and Central Americans, derived from Asian population studies [44]. However, the assignment of these cutoff points does not fit the ethnic characteristics of the entire population living in these regions [45], such as the Brazilian population. Brazil has a highly heterogeneous population, with interethnic admixtures of people from European, African and indigenous backgrounds [46]. A recent study on the genomic ancestry of different geographical regions of Brazil has ratified the predominance of European ancestry among Brazilians [24]. Thus, the use of $\geq 102 \mathrm{~cm}$ for men and $\geq 88 \mathrm{~cm}$ for women as WC cut points in our study was a pragmatic decision based on the above rationale, as recognized in the 2009 harmonized consensus [3]. Further studies are needed to define the WC cut points representative of the Brazilian population.

Our study identified education as a protective factor against MetS in women (PR 0.66, 95\% CI: 0.49-0.89), which is in agreement with other studies [21,36,47]. Analyzing the age category (results not shown), women with 12 or more years of schooling tended to be in the younger categories. The increased number of women with 12 or more years of education is a recent phenomenon in Brazil [48], and it may partly explain the observed result. Among South Koreans, women with less education tended to be in the older birth cohorts and had a higher prevalence of 
Table 3 Prevalence (\%), crude and adjusted prevalence ratios of metabolic syndrome among male adults aged 18 years $\operatorname{or}$ older $^{\text {, }}$ by selected sociodemographic, behavioral, nutritional and health status variables (Federal District, Brazil, 2007)

\begin{tabular}{|c|c|c|c|c|c|c|c|c|}
\hline & \multicolumn{2}{|c|}{ Prevalence $(95 \% \mathrm{Cl})$} & \multicolumn{6}{|c|}{ Prevalence ratio $(95 \% \mathrm{Cl})$} \\
\hline & & & \multicolumn{2}{|r|}{ Crude } & \multicolumn{2}{|c|}{ Adjusted $^{b}$} & \multicolumn{2}{|c|}{ Adjusted $^{c}$} \\
\hline \multicolumn{9}{|l|}{ Age (years) } \\
\hline $18-24$ & 7.3 & $(0.0-14.8)$ & 1 & & 1 & & 1 & \\
\hline $25-34$ & 24.4 & $(16.0-32.7)$ & 3.35 & $(1.27-8.88)$ & 3.35 & $(1.27-8.88)$ & 2.47 & $(1.15-5.33)$ \\
\hline $35-44$ & 35.4 & $(26.3-44.4)$ & 4.87 & $(1.94-12.2)$ & 4.87 & $(1.94-12.2)$ & 3.06 & $(1.44-6.51)$ \\
\hline $45-54$ & 55.3 & $(44.2-66.4)$ & 7.60 & $(3.08-18.7)$ & 7.60 & $(3.08-18.7)$ & 3.70 & $(1.73-7.87)$ \\
\hline $55-64$ & 65.1 & $(50.5-79.7)$ & 8.95 & $(3.64-22.0)$ & 8.95 & $(3.64-22.0)$ & 4.17 & $(1.96-8.86)$ \\
\hline$\geq 65$ & 57.4 & $(41.7-73.1)$ & 7.89 & $(3.14-19.8)$ & 7.89 & $(3.14-19.8)$ & 4.25 & $(1.97-9.17)$ \\
\hline \multicolumn{9}{|c|}{ Residence time in Federal District (years) } \\
\hline$<10$ & 20.8 & $(9.9-31.8)$ & 1 & & 1 & & & \\
\hline $10-19$ & 24.8 & $(15.8-33.8)$ & 1.19 & $(0.63-2.25)$ & 1.17 & $(0.65-2.10)$ & & \\
\hline $20-29$ & 26.6 & $(16.6-36.6)$ & 1.28 & $(0.70-2.33)$ & 1.17 & $(0.68-2.00)$ & & \\
\hline$\geq 30$ & 45.5 & $(38.6-52.4)$ & 2.19 & $(1.30-3.67)$ & 1.16 & $(0.70-1.94)$ & & \\
\hline \multicolumn{9}{|l|}{ Marital status } \\
\hline Single & 14.8 & $(8.7-20.9)$ & 1 & & 1 & & & \\
\hline Married/living with partner & 41.4 & $(35.0-47.7)$ & 2.79 & $(1.74-4.47)$ & 1.36 & $(0.78-2.35)$ & & \\
\hline Widowed/separated & 43.4 & $(16.4-70.4)$ & 2.93 & $(1.47-5.84)$ & 1.21 & $(0.62-2.37)$ & & \\
\hline \multicolumn{9}{|l|}{ Current physical activity level } \\
\hline Active & 26.3 & $(20.5-32.2)$ & 1 & & 1 & & & \\
\hline Insufficiently active & 35.6 & $(22.2-49.0)$ & 1.35 & $(0.90-2.03)$ & 1.24 & $(0.86-1.79)$ & & \\
\hline Inactive & 41.8 & $(29.9-53.6)$ & 1.58 & $(1.13-2.22)$ & 1.23 & $(0.92-1.63)$ & & \\
\hline \multicolumn{9}{|l|}{ Body mass index $\left(\mathrm{kg} / \mathrm{m}^{2}\right)$} \\
\hline Normal $(<25)$ & 6.4 & $(3.3-9.4)$ & 1 & & 1 & & 1 & \\
\hline Overweight(25-29) & 38.4 & $(31.8-44.9)$ & 6.03 & $(3.52-10.3)$ & 4.52 & $(2.64-7.74)$ & 4.40 & $(2.57-7.55)$ \\
\hline Obese $(\geq 30)$ & 84.9 & $(73.7-96.1)$ & 13.3 & $(8.05-22.1)$ & 9.99 & $(5.92-16.9)$ & 9.77 & $(5.79-16.5)$ \\
\hline \multicolumn{9}{|l|}{ Total cholesterol (mg/dL) } \\
\hline$<200$ & 23.4 & $(17.2-29.6)$ & 1 & & 1 & & 1 & \\
\hline$\geq 200$ & 42.9 & $(34.6-51.1)$ & 1.83 & $(1.32-2.54)$ & 1.43 & $(1.08-1.91)$ & 1.14 & $(0.91-1.42)$ \\
\hline
\end{tabular}

MetS [47]. In women, the cumulative effect of poor socioeconomic status during childhood and adulthood, including education, seems to influence the risk of MetS [49]. An assessment of potential mediators of educational inequalities in our population in the context of the transition process in developing countries and how they affect men and women differently could identify the best exponents of this phenomenon.

Likely limitations of our study are related to the nature of cross-sectional studies, including the potential for survival bias and temporal ambiguity. Considering that diagnostic factors and other correlates that constitute MetS may fluctuate over time, the diagnostic accuracy may increase with subsequent data acquisition. In our sample, women were clearly over-represented, but we minimized this effect by applying adjustment methods. The strengths of this study lie in the probabilistic sampling and the use of prevalence ratios in the multivariate analyses, making these results a sound basis for planning public health interventions.

\section{Conclusions}

In conclusion, our study revealed that $32.0 \%$ of the adult population of Brazil's FD had MetS in 2007. The components of this syndrome were gender-specific, and education was protective for women. The study enabled a sound measure of MetS for data comparison and suggests that reducing education inequalities may be an important public policy goal to improve health outcomes, especially among women. 
Table 4 Prevalence (\%), crude and adjusted prevalence ratios of metabolic syndrome among female adults aged 18 years or older ${ }^{a}$, by selected sociodemographic, behavioral, nutritional and health status variables (Federal District, Brazil, 2007)

Prevalence $(95 \% \mathrm{Cl})$

\begin{tabular}{cc} 
& Prevalence ratio $(95 \% \mathrm{Cl})$ \\
\hline Crude & Adjusted $^{\mathbf{b}}$
\end{tabular}

Age (years)

\begin{tabular}{|c|c|c|c|c|c|c|c|c|}
\hline $18-24$ & 10.3 & $(3.7-17.0)$ & 1 & & 1 & & 1 & \\
\hline $25-34$ & 21.3 & $(16.0-26.5)$ & 2.06 & $(1.13-3.74)$ & 2.06 & $(1.13-3.74)$ & 1.67 & $(0.98-2.83)$ \\
\hline $35-44$ & 37.4 & $(31.6-43.2)$ & 3.62 & $(2.04-6.44)$ & 3.62 & $(2.04-6.44)$ & 2.18 & $(1.31-3.66)$ \\
\hline $45-54$ & 56.0 & $(47.2-64.9)$ & 5.42 & $(3.08-9.55)$ & 5.42 & $(3.08-9.55)$ & 2.72 & $(1.61-4.60)$ \\
\hline $55-64$ & 67.9 & $(59.7-76.1)$ & 6.57 & $(3.74-11.55)$ & 6.57 & $(3.74-11.55)$ & 2.88 & $(1.69-4.90)$ \\
\hline$\geq 65$ & 77.0 & $(68.4-85.5)$ & 7.45 & $(4.23-13.11)$ & 7.45 & $(4.23-13.11)$ & 3.31 & $(1.90-5.75)$ \\
\hline \multicolumn{9}{|l|}{ Education (years) } \\
\hline $0-8$ & 43.5 & $(37.2-49.7)$ & 1 & & 1 & & 1 & \\
\hline $9-11$ & 24.7 & $(20.5-29.0)$ & 0.57 & $(0.46-0.70)$ & 0.78 & $(0.64-0.96)$ & 0.87 & $(0.73-1.04)$ \\
\hline$\geq 12$ & 20.5 & $(14.4-26.6)$ & 0.47 & $(0.33-0.67)$ & 0.51 & $(0.37-0.70)$ & 0.66 & $(0.49-0.89)$ \\
\hline \multicolumn{9}{|c|}{ Residence time in Federal District (years) } \\
\hline$<10$ & 21.9 & $(14.7-29.1)$ & 1 & & 1 & & & \\
\hline $10-19$ & 28.8 & $(23.1-34.5)$ & 1.31 & $(0.93-1.85)$ & 1.14 & $(0.83-1.57)$ & & \\
\hline $20-29$ & 28.8 & $(23.1-34.5)$ & 1.31 & $(0.93-1.85)$ & 1.14 & $(0.83-1.57)$ & & \\
\hline$\geq 30$ & 49.7 & $(43.8-55.7)$ & 2.27 & $(1.70-3.03)$ & 1.10 & $(0.82-1.47)$ & & \\
\hline \multicolumn{9}{|l|}{ Marital status } \\
\hline Single & 20.3 & $(15.5-25.2)$ & 1 & & 1 & & 1 & \\
\hline Married/living with partner & 34.8 & $(30.0-39.6)$ & 1.71 & $(1.32-2.22)$ & 1.22 & $(0.95-1.57)$ & 0.95 & $(0.77-1.17)$ \\
\hline Widowed/separated & 58.3 & $(50.4-66.1)$ & 2.87 & $(2.20-3.74)$ & 1.28 & $(0.99-1.66)$ & 1.03 & $(0.83-1.29)$ \\
\hline \multicolumn{9}{|l|}{ Extra table salt } \\
\hline No & 35.0 & $(30.8-39.2)$ & 1 & & 1 & & & \\
\hline Yes & 28.0 & $(20.7-35.3)$ & 0.80 & $(0.64-1.00)$ & 0.92 & $(0.75-1.12)$ & & \\
\hline \multicolumn{9}{|l|}{ Alcohol consumptiong } \\
\hline Never & 36.8 & $(32.7-40.8)$ & 1 & & 1 & & 1 & \\
\hline No abusive & 23.8 & $(15.8-31.9)$ & 0.65 & $(0.49-0.86)$ & 0.74 & $(0.55-0.99)$ & 0.90 & $(0.69-1.17)$ \\
\hline Abusive & 21.7 & $(10.4-33.0)$ & 0.59 & $(0.36-0.97)$ & 0.75 & $(0.50-1.13)^{\mathrm{e}}$ & 0.71 & $(0.48-1.04)$ \\
\hline \multicolumn{9}{|l|}{ Smoking } \\
\hline Never & 29.4 & $(25.7-33.1)$ & 1 & & 1 & & & \\
\hline Former smokers & 55.0 & $(45.0-65.0)$ & 1.87 & $(1.54-2.28)$ & 1.41 & $(1.18-1.67)$ & & \\
\hline Current smokers & 34.2 & $(23.7-44.7)$ & 1.16 & $(0.88-1.53)$ & 1.12 & $(0.86-1.46)$ & & \\
\hline \multicolumn{9}{|l|}{ Body mass index $\left(\mathrm{kg} / \mathrm{m}^{2}\right)$} \\
\hline Normal $(<25)$ & 8.4 & $(6.1-10.6)$ & 1 & & 1 & & 1 & \\
\hline Overweight(25-29) & 45.5 & $(38.3-52.8)$ & 5.45 & $(4.13-7.20)$ & 4.29 & $(3.21-5.75)$ & 4.09 & $(3.07-5.46)$ \\
\hline Obese $(\geq 30)$ & 78.1 & $(72.6-83.5)$ & 9.34 & $(7.20-12.1)$ & 7.04 & $(5.32-9.31)$ & 6.78 & $(5.15-8.92)$ \\
\hline \multicolumn{9}{|l|}{ Total cholesterol (mg/dL) } \\
\hline$<200$ & 25.5 & $(20.7-30.3)$ & 1 & & 1 & & 1 & \\
\hline$\geq 200$ & 46.1 & $(40.7-51.6)$ & 1.81 & $(1.52-2.16)$ & 1.21 & $(1.02-1.43)$ & 1.20 & $(1.05-1.36)$ \\
\hline \multicolumn{9}{|l|}{ LDLc (mg/dL) } \\
\hline$<130$ & 28.1 & $(23.7-32.5)$ & 1 & & 1 & & & \\
\hline $130-159$ & 36.3 & $(30.2-42.4)$ & 1.29 & $(1.05-1.58)$ & 0.99 & $(0.82-1.19)$ & & \\
\hline$\geq 160$ & 52.3 & $(43.9-60.7)$ & 1.86 & $(1.49-2.33)$ & 1.09 & $(0.90-1.32)$ & & \\
\hline
\end{tabular}

${ }^{a}$ Weighted to represent distributions of population aged 18 years or older, according to gender, age and education based on Brazilian national census for the year 2000 .

${ }^{b}$ Adjusted for age.

c Adjusted for age, education, marital status, alcohol consumption, body mass index and total cholesterol. 


\section{Competing interests}

The authors declare that they have no competing interests.

\section{Authors' contributions}

ESD undertook execution, analysis and wrote the first draft of the manuscript. ESM contributed with statistical analyses. KMBC, EM and MKI contributed in the design, execution and critical discussion of the study. All authors read and approved the final manuscript.

\section{Acknowledgments}

This work was supported by Fundação de Apoio à Pesquisa do Distrito Federal-FAPDF [193.000.067/2005] and Fundação Nacional de Saúde/ Ministério da Saúde [25000.132765/2006-32]. The authors are grateful to Dr. Erly Catarina de Moura for her contribution during data analyses.

\section{Author details}

${ }^{1}$ Programa de Pós-graduação em Ciências da Saúde, Faculdade de Ciências da Saúde, Universidade de Brasília, Campus Darcy Ribeiro, Brasília, DF 70910900, Brazil. ${ }^{2}$ Programa de Pós-graduação em Nutrição Humana, Faculdade de Ciências da Saúde, Universidade de Brasília, Brasília, DF 70910-900, Brazil. 3 Departamento de Estatística, Universidade de Brasília, Brasília, DF 70910-900, Brazil. ${ }^{4}$ Departamento de Saúde Coletiva, Faculdade de Ciências da Saúde, Universidade de Brasília, Brasília, DF 70910-900, Brazil.

Received: 14 October 2011 Accepted: 13 March 2012

Published: 14 May 2012

\section{References}

1. Gaziano TA, Bitton A, Anand S, Abrahams-Gessel S, Murphy A: Growing epidemic of coronary heart disease in low- and middle-income countries. Curr Probl Cardiol 2010, 35:72-115.

2. Gersh BJ, Sliwa K, Mayosi BM, Yusuf S: Novel therapeutic concepts: the epidemic of cardiovascular disease in the developing world: global implications. Eur Heart J 2010, 31:642-648.

3. Alberti K, Eckel R, Grundy S, Zimmet P, Cleeman J, Donato K, Fruchart J, James W, Loria C, Smith S: Harmonizing the metabolic syndrome: a joint interim statement of the International Diabetes Federation Task Force on Epidemiology and Prevention; National Heart, Lung, and Blood Institute; American Heart Association; World Heart Federation; International Atherosclerosis Society; and International Association for the Study of Obesity. Circulation 2009, 120:1640-1645.

4. Ford ES, Li C, Sattar N: Metabolic syndrome and incident diabetes: current state of the evidence. Diabetes Care 2008, 31:1898-1904.

5. Gami AS, Witt BJ, Howard DE, Erwin PJ, Gami LA, Somers VK, Montori VM: Metabolic syndrome and risk of incident cardiovascular events and death: a systematic review and meta-analysis of longitudinal studies. J Am Coll Cardiol 2007, 49:403-414.

6. Wilson PW, D'Agostino RB, Parise H, Sullivan L, Meigs JB: Metabolic syndrome as a precursor of cardiovascular disease and type 2 diabetes mellitus. Circulation 2005, 112:3066-3072.

7. Bayturan O, Tuzcu EM, Lavoie A, Hu T, Wolski K, Schoenhagen P, Kapadia S, Nissen SE, Nicholls SJ: The metabolic syndrome, its component risk factors, and progression of coronary atherosclerosis. Arch Intern Med 2010, 170:478-484.

8. Mente A, Yusuf S, Islam S, McQueen MJ, Tanomsup S, Onen CL, Rangarajan S, Gerstein HC, Anand SS: Metabolic syndrome and risk of acute myocardial infarction a case-control study of 26,903 subjects from 52 countries. J Am Coll Cardiol 2010, 55:2390-2398.

9. Simmons RK, Alberti KG, Gale EA, Colagiuri S, Tuomilehto J, Qiao Q, Ramachandran A, Tajima N, Brajkovich Mirchov I, Ben-Nakhi A, Reaven G, Hama Sambo B, Mendis S, Roglic G: The metabolic syndrome: useful concept or clinical tool? Report of a WHO Expert Consultation. Diabetologia 2010, 53:600-605.

10. Cameron A: The metabolic syndrome: validity and utility of clinical definitions for cardiovascular disease and diabetes risk prediction. Maturitas 2010, 65:117-121.

11. Misra A, Khurana L: Obesity and the metabolic syndrome in developing countries. J Clin Endocrinol Metab 2008, 93(Suppl 1):9-30.

12. Batsis JA, Nieto-Martinez RE, Lopez-Jimenez F: Metabolic syndrome: from global epidemiology to individualized medicine. Clin Pharmacol Ther 2007, 82:509-524.
13. Cornier MA, Dabelea D, Hernandez TL, Lindstrom RC, Steig AJ, Stob NR, Van Pelt RE, Wang H, Eckel RH: The metabolic syndrome. Endocr Rev 2008 29:777-822.

14. Executive Panel on Detection Evaluation and Treatment of High Blood Cholesterol in Adults: Executive summary of the third report of the National Cholesterol Education Program (NCEP) expert panel on detection, evaluation, and treatment of high blood cholesterol in adults (Adult Treatment Panel III). JAMA 2001, 285:2486-2497.

15. Escobedo J, Schargrodsky H, Champagne B, Silva H, Boissonnet CP, Vinueza R, Torres M, Hernandez R, Wilson E: Prevalence of the metabolic syndrome in Latin America and its association with sub-clinical carotid atherosclerosis: the CARMELA cross sectional study. Cardiovasc Diabeto/ 2009, 26:52-60.

16. Finucane MM, Stevens GA, Cowan MJ, Danaei G, Lin JK, Paciorek CJ, Singh GM, Gutierrez HR, Lu Y, Bahalim AN, Farzadfar F, Riley LM, Ezzati M: National, regional, and global trends in body-mass index since 1980: systematic analysis of health examination surveys and epidemiological studies with 960 country-years and 9. 1 million participants. Lancet 2011, 377:557-567.

17. Schmidt MI, Duncan BB, Azevedo e Silva G, Menezes AM, Monteiro CA, Barreto SM, Chor D, Menezes PR: Chronic non-communicable diseases in Brazil: burden and current challenges. Lancet 2011, 377:1949-1961.

18. Barbosa PJ, Lessa I, de Almeida Filho N, Magalhães LB, Araújo J: Criteria for central obesity in a Brazilian population: impact on metabolic syndrome. Ara Bras Cardiol 2006, 87:407-414.

19. Marquezine GF, Oliveira CM, Pereira AC, Krieger JE, Mill JG: Metabolic syndrome determinants in an urban population from Brazil: social class and gender-specific interaction. Int J Cardiol 2008, 129:259-265.

20. Silventoinen K, Pankow J, Jousilahti P, Hu G, Tuomilehto J: Educational inequalities in the metabolic syndrome and coronary heart disease among middle-aged men and women. Int J Epidemio/ 2005, 34:327-334.

21. Loucks EB, Rehkopf DH, Thurston RC, Kawachi I: Socioeconomic disparities in metabolic syndrome differ by gender: evidence from NHANES III. Ann Epidemiol 2007, 17:19-26.

22. Demographic Census 2000 - Brazil. [http://www.ibge.gov.br/english/ estatistica/populacao/censo2000/]

23. Friedewald WT, Levy RI, Fredrickson DS: Estimation of the concentration of low-density lipoprotein cholesterol in plasma, without use of the preparative ultracentrifuge. Clin Chem 1972, 18:499-502.

24. Pena SDJ, Di Pietro G, Fuchshuber-Moraes M, Genro JP, Hutz MH, Kehdy FSG, Kohlrausch F, Magno LAV, Montenegro RC, Moraes MO, Moraes MEA, Moraes MR, Ojopi EB, Perini JA, Racciopi Cl, Ribeiro-dos-Santos AKC, Rios-Santos F, Romano-Silva MA, Sortica VA, Suarez-Kurtz G: The genomic ancestry of individuals from different geographical regions of Brazil is more uniform than expected. PLOS ONE 2011, 6:e17063.

25. Craig $C L$, Marshall $A L$, Sjöström M, Bauman AE, Booth ML, Ainsworth BE, Pratt M, Ekelund U, Yngve A, Sallis JF, Oja P: International physical activity questionnaire: 12- country reliability and validity. Med Sci Sports Exerc 2003, 35:1381-1395.

26. Haskell WL, Lee IM, Pate RR, Powell KE, Blair SN, Franklin BA, Macera CA, Heath GW, Thompson PD, Bauman A: Physical activity and public health: updated recommendation for adults from the American College of Sports Medicine and the American Heart Association. Med Sci Sports Exerc 2007, 39:1423-1434.

27. Barros AJ, Hirakata VN: Alternatives for logistic regression in crosssectional studies: an empirical comparison of models that directly estimate the prevalence ratio. BMC Med Res Methodol 2003, 3:21.

28. Monteiro CA, Conde WL, Popkin BM: Income-specific trends in obesity in Brazil: 1975-2003. Am J Public Health 2007, 97:1808-1812.

29. Moura EC, Claro RM: Estimates of obesity trends in Brazil, 2006-2009. Int J Public Health, in press.

30. Ervin RB: Prevalence of metabolic syndrome among adults 20 years of age and over, by sex, age, race and ethnicity, and body mass index: United States, 2003-2006. Natl Health Stat Report 2009, 13:1-7.

31. Florez H, Silva E, Fernández V, Ryder E, Sulbarán T, Campos G, Calmón G, Clavel E, Castillo-Florez S, Goldberg R: Prevalence and risk factors associated with the metabolic syndrome and dyslipidemia in White, Black, Amerindian and Mixed Hispanics in Zulia State, Venezuela. Diabetes Res Clin Pract 2005, 69:63-77.

32. Gelaye B, Revilla L, Lopez T, Sanchez S, Williams MA: Prevalence of metabolic syndrome and its relationship with leisure time physical activity among Peruvian adults. Eur J Clin Invest 2009, 39:891-898. 
33. Ramachandran A, Snehalatha C, Satyavani K, Sivasankari S, Vijay V: Metabolic syndrome in urban Asian Indian adults-a population study using modified ATP III criteria. Diabetes Res Clin Pract 2003, 60:199-204.

34. Amuna P, Zotor FB: Epidemiological and nutrition transition in developing countries: impact on human health and development. Proc Nutr Soc 2008, 67:82-90

35. Chow CK, Lock K, Teo K, Subramanian SV, McKee M, Yusuf S: Environmental and societal influences acting on cardiovascular risk factors and disease at a population level: a review. Int J Epidemiol 2009, 38:1580-1594.

36. Salsberry PJ, Corwin E, Reagan PB: A complex web of risks for metabolic syndrome: race/ethnicity, economics, and gender. Am J Prev Med 2007, 33:114-120.

37. Dekker JM, Girman C, Rhodes T, Nijpels G, Stehouwer CD, Bouter LM, Heine RJ: Metabolic syndrome and 10-year cardiovascular disease risk in the Hoorn Study. Circulation 2005, 112:666-673.

38. MCNeill AM, Rosamond WD, Girman CJ, Golden SH, Schmidt MI, East HE, Ballantyne CM, Heiss G: The metabolic syndrome and 11-year risk of incident cardiovascular disease in the atherosclerosis risk in communities study. Diabetes Care 2005, 28:385-390.

39. Knuiman MW, Hung J, Divitini ML, Davis TM, Beilby JP: Utility of the metabolic syndrome and its components in the prediction of incident cardiovascular disease: a prospective cohort study. Eur J Cardiovasc Prev Rehabil 2009, 16:235-241

40. World Health Organization: Global health risks: mortality and burden of disease attributable to selected major risks. Geneva; 2009.

41. Santos AC, Severo M, Barros $\mathrm{H}$ : Incidence and risk factors for the metabolic syndrome in an urban South European population. Prev Med 2010, 50:99-105.

42. Despre's JP, Lemieux I: Abdominal obesity and metabolic syndrome. Nature 2006, 444:881-887.

43. Khunti K, Taub N, Tringham J, Jarvis J, Farooqi A, Skinner TC, Davies MJ: Screening for the metabolic syndrome using simple anthropometric measurements in south Asian and white Europeans: a population-based screening study. The Leicester Ethnic Atherosclerosis and Diabetes Risk (LEADER) Study. Prim Care Diabetes 2010, 4:25-32.

44. Alberti $K$, Zimmet $P$, Shaw J: The metabolic syndrome-a new worldwide definition. Lancet 2005, 366:1059-1062.

45. Cuevas A, Alvarez V, Carrasco F: Epidemic of metabolic syndrome in Latin America. Curr Opin Endocrinol Diabetes Obes 2011, 18:134-138.

46. Alves-Silva J, da Silva Santos M, Guimarães PE, Ferreira AC, Bandelt HJ, Pena SD, Prado VF: The ancestry of Brazilian mtDNA lineages. Am J Hum Genet 2000, 67:444-461.

47. Kim MH, Kim MK, Choi BY, Shin YJ: Educational disparities in the metabolic syndrome in a rapidly changing society-the case of South Korea. Int $J$ Epidemiol 2005, 34:1266-1273.

48. Beltrão Kl, Alves JED: A reversão do hiato de gênero na educação brasileira no século XX. Cad Pesqui 2009, 39:125-156.

49. Chichlowska KL, Rose KM, Diez-Roux AV, Golden SH, McNeill AM, Heiss G Life course socioeconomic conditions and metabolic syndrome in adults: the Atherosclerosis Risk in Communities (ARIC) Study. Ann Epidemiol 2009, 19:875-883.

doi:10.1186/1758-5996-4-20

Cite this article as: Dutra et al:: Metabolic syndrome in central Brazil: prevalence and correlates in the adult population. Diabetology \& Metabolic Syndrome 2012 4:20.

\section{Submit your next manuscript to BioMed Central and take full advantage of:}

- Convenient online submission

- Thorough peer review

- No space constraints or color figure charges

- Immediate publication on acceptance

- Inclusion in PubMed, CAS, Scopus and Google Scholar

- Research which is freely available for redistribution 